Article

\title{
Enduring Features of the North American Suburb: Built Form, Automobile Orientation, Suburban Culture and Political Mobilization
}

\author{
Pierre Filion \\ School of Planning, University of Waterloo, Waterloo, ON N2L 3G1, Canada; E-Mail: pfilion@uwaterloo.ca
}

Submitted: 9 July 2018 | Accepted: 24 August 2018 | Published: 30 October 2018

\begin{abstract}
As any social phenomenon, the evolution of suburbs can be seen as at the confluence of two contradictory sets of forces. There are first forces of change, which propel suburbs in new directions. Much of the present literature on suburbs highlights suburban transitions in the form of social and economic diversification, and of new forms of development. The article attempts to rebalance the discourse on suburbs by emphasizing forces of durability. It does not deny the importance of observed suburban transitions, but argues that there is, at the heart of North American suburbs, an enduring automobility-induced transportation dynamic, which reverberates on most aspects of suburbs. The article explores the mechanisms undergirding suburban durability by linking the suburban transportation dynamic to the self-reproductive effects of a suburban lifestyle and culture and their political manifestations. These forces impede planning attempts to transform suburbs in ways that make them more environmentally sustainable. To empirically ground its argument, the article draws on two Toronto region case studies illustrating processes assuring the persistence of the durable features of North American suburbs: the layout of large suburban multifunctional centres and the themes raised by Rob Ford during his successful 2010 mayoralty electoral campaign.
\end{abstract}

\section{Keywords}

automobile dependence; land use; North America; suburb; super grid; Toronto; transportation

\section{Issue}

This article is part of the issue "Urban Planning and the Suburbs: Solutions for Sustainability from the Edges", edited by Markus Moos (University of Waterloo, Canada).

(C) 2018 by the author; licensee Cogitatio (Lisbon, Portugal). This article is licensed under a Creative Commons Attribution 4.0 International License (CC BY).

\section{Introduction}

While most of the literature emphasizes the transformation and diversity of the North American suburb, the present article concentrates on enduring fundamental features present across these suburbs. The literature demonstrates how suburbs have become socially and functionally diversified, to the extent that some observers now use the expression "post-suburban" to connote the new suburban reality (Hayden, 2003; Kelly, 1993; Phelps, Wood, \& Valler, 2010). The transformative theme also pervades a planning literature, often driven by environmental objectives, that calls for a radical change of suburbs. The article attempts to rebalance the discourse on North American suburbs by bringing to light factors of suburban stability. It concentrates on the automobile-oriented transportation dynamic of these suburbs, contending that this dynamic reverberates on most dimensions of suburbs, including those the literature associates with their transformation. The suburban transportation dynamic therefore assures that, regardless of the extent to which the constituents of the suburb (income and ethnic/racial groups, economic activities, etc.) change, there is a fundamentally suburban dimension to the way people live and organizations operate in suburban areas. What is more, the influence of the land-use and transportation dynamic on behaviour gives rise to a suburban culture, which finds political expression. Once politicized, suburban culture becomes a further contributor to the endurance of prevailing suburban built forms and journey patterns. Not only are these fundamental features of suburbs factors of subur- 
ban stability but they also contribute to a common suburban identity. Interest in suburban factors of stability is of particular relevance at a time when planning promotes suburban transformations intended to enhance environmental sustainability, largely by reducing suburban land consumption and reliance on the automobile. It is important for such planning strategies to be aware of the obstacles they will encounter. This is how the article contributes to the suburban sustainability theme of this special issue.

The exploration of the North American variant of the suburban phenomenon is illustrated by two brief case studies, both originating from the Toronto metropolitan region: 1) the difficulty for large suburban multifunctional centres to depart from the car-dominated nature of the suburban realm; 2 ) the themes raised during the 2010 electoral campaign of Mayor Rob Ford, representing a manifestation of suburban populism. The two cases contribute to the argument of the article by highlighting mechanisms perpetuating prevailing suburban land-use and transportation patterns.

\section{Post-Suburbs: Diversification of the Suburb}

The North American suburban form that has evolved since WWII constitutes the object of this article. If streetcar and subway suburbs can be perceived as extensions of the central-city morphology, this is not the case for the post-war automobile-dependent suburb. Any metropolitan-scale aerial imagery exposes the deep urban development transition that took place from the late 1940s. With the generalization of car use, accessibility improved, thereby allowing a more liberal consumption of space. Hence the association of the post-war suburb with low density and abundant greenspace (Carr \& Whitehand, 2001; Rowe, 1991).

In the early post-WWII decades, suburban development was propelled by rapid population and household formation in prosperous economic times. Young families were attracted by spacious housing units (relative to central-city dwellings) and plentiful green space (Harris, 2004; Waldie, 1996). In the U.S., suburbanization was further fuelled by the white flight phenomenon (Boustan, 2010). Both in the U.S. and Canada, post-war suburbs were initially largely populated by young middleclass households.

The North American suburb experienced accelerating social diversification from the 1970 s and $1980 \mathrm{~s}$. Several factors concurred to transform North American suburbs. There is first the fact that suburbs became the majority of the metropolitan region in terms of area, population and economic activity. It followed that most forms of development sought suburban rather than central-city locations (Weitz \& Crawford, 2012). Moreover, the combination of aging in place and the suburban presence of most housing in the metropolitan region made for a more even age group distribution than in the early postwar decades (Lee, Hong, \& Park, 2017).
Over time, inner suburbs often acquired the social characteristics of adjacent central-city areas, another factor of suburban diversification (Lo, Preston, Anisef, Basu, \& Wang, 2015; Lucy \& Phillips, 2000; Murphy, 2007; Short, Hanlon, \& Vicino, 2007). Meanwhile, suburbs became ports of entry for immigrants, breaking with the traditional concentric social integration process described by the Chicago School of the 1920s (Park, Burgess, \& McKenzie, 1925). In its view, immigrants first settled in central-city transitional neighbourhoods and gradually moved further out at a rate that coincided with their assimilation to mainstream society. Over the last decades, new clusters of immigrants transformed the retailing and institutional scene of suburbs, leading to the emergence of the "ethnoburb" phenomenon (Li, 2009; Li, Skop, \& $\mathrm{Yu}, 2016)$. Meanwhile, suburbs became economically diversified as they attracted research and development as well as head offices (Bresnahan \& Gambardella, 2004; Mozingo, 2011). The diversification of the suburb is also reflected in the different trajectories taken by suburbs, some prosperous, others in decline, some socially mixed, others stubbornly exclusionary. There are also the differences between U.S. and Canadian suburbs, expressing distinct political and planning regimes and attitudes towards race and public sector intervention (Adams, 2003).

Not surprisingly, such attention to suburban transformations has led researchers to conclude, some more categorically than others, that we are entering a postsuburban era, marking a radical break with the suburban reality that has evolved with some continuity since WWII (Keil \& Addie, 2015; Mace, 2013; Phelps, 2015; Phelps \& $\mathrm{Wu}, 2011$; Teaford, 1997, 2011). The remainder of the article contends that, despite these transformations, there are durable automobility-related features at the heart of the North American suburban phenomenon, which are responsible for enduring and distinct suburban features pertaining to built form, journey patterns, lifestyle, culture and political expression.

\section{Suburban Distinctiveness}

\subsection{The Super Grid and Automobile Dependence}

All dimensions of suburban form and dynamics are impacted by heavy reliance on the car. For example, the presence of abundant green spaces in suburbs, would they be parks, natural areas or private lawns, was made possible by the relaxation of proximity requirements brought on by the generalization of car use. Plentiful accessible space in suburbs also caused a modification of built forms, as evidenced by the passage from centralcity multi-storey to suburban single-storey manufacturing. In addition, the need to accommodate cars at every origin and destination, translated into an adaptation of buildings and the introduction of new architectural concepts: for example, single-family homes with garages and driveways, the shopping mall with its sea of parking, various forms of drive-in and drive-through formats. 
Most impactful on behaviour in the suburb has been the mutual adaptation between land-use patterns and high levels of car use (Marshall, 2000). Generalized reliance on the automobile has made it possible to create large monofunctional zones, a distribution that results in a dispersion of origins and destinations (Hirt, 2014). Such dispersion, especially within large specialized zones, can only be served efficiently by the car (Bae, 2004; Pushkarev \& Zupan, 1977). Not only does zonal functional segregation stimulate reliance of the car, but such a land-use configuration is made all the more pressing by the negative externalities generated by heavy car traffic generators.

In the North American context, the above-described land use-transportation relation translated into an urban form that rapidly became ubiquitous across the continent's suburban areas: the super grid. Early in the evolution of the post-WWII suburb, the super grid emerged as a response to the need to accommodate large traffic flows while preserving the safety and tranquility of (mostly low-density) residential areas. The super grid is made of arterials and, occasionally, expressways. It provides borderlines for super blocks. The super grid can be perceived as the land-use and transportation organizing principle of the North American suburb. While the essence of the super grid model is present in virtually all North American suburban areas, the super grid rarely adopts a symmetrical form, forced as it is to adjust to: topography; the presence of land uses, such as airports and marshalling yards, whose size far exceeds that of a super block; and municipal fragmentation when it prevents the integration of road, and thus super grid, networks.

The super grid configuration is adapted to the transportation and land-use requirements of the North American suburb. It provides a road network capable of absorbing the volume of traffic generated by near total dependence on the car (Southworth \& Ben-Joseph, 1995; Southworth \& Owens, 1993). As in this type of configuration car traffic circulates most fluidly when origins and destinations are dispersed in low-density built environments, concentrations of activities and high-density developments can be sources of congestion (Cervero, 2013). The super grid model also lends itself to the separation of land uses within suburbs, arterials and expressways being obvious dividers (Charmes, 2010; Dear \& Flusty, 1998). It is indeed usual to find super blocks devoted to a single dominant land use.

In summary, from a transportation and land-use perspective, the North American suburban phenomenon is distinguished by near total dependence on the automobile and an adaptation of land use to this dependence in the form of functional specialization and relatively low density. ${ }^{1}$ Most North American suburbs also share reliance on the super grid formula, which configures the relationship between transportation and land use. Com- mon transportation and land-use structuring features provide a shared identity to North American suburbs, which are otherwise differentiated by their varied social and economic characteristics.

\subsection{Daily Life, Suburban Culture and Political Expression}

The combined effects of suburban land-use patterns and reliance on the automobile reverberate on behaviour taking place within the suburban realm. For example, specialized space, made possible by heavy automobile reliance, thus translates into programmed behaviour because of long distances between different types of suburban land uses (Badoe \& Miller, 2000; Franck \& Stevens, 2006; van Wee, 2002; Zhang, 2006). In addition, those who do not have access to a car (or whose access is limited), as is the case for the young, the old, the handicapped who cannot drive and the poor, are more spatially and activity constrained in suburbs than in higher density and more multifunctional settings (Blumenberg, 2004; Hu, 2015; Spinney, Scott, \& Newbold, 2009; Walks \& Tanter, 2014).

Common living conditions emanating from the transportation and land-use patterns present across North American suburbs give rise to a shared culture, which transcends their increased social and economic diversity. This suburban culture is a function of mutual lived experiences relating to the transportation and land-use patterns responsible for the distinct identity of the suburban realm. While generally seen as a manifestation of a broad consumerist societal culture, suburban daily life can itself be perceived as contributing to the formation of a distinct suburban culture (de Certeau, 1984; Highmore, 2002a, 2002b; Lefebvre, 1991). In the present understanding, suburban culture derives from daily life shaped by single-family homes with their plentiful indoor and outdoor space, other forms of housing also well provided with outdoor space, abundant green space and major suburban destinations such as shopping malls. Common suburban experiences also include time spent in the car, given the significant share of suburbanites' time automobile journeys take (e.g., Banham, 1971). Much of the world view of suburban residents is fashioned by what they see through the windshields of their cars (Walks, 2014). Irrespective of their age, income and ethnic/racial group, suburbanites share, albeit with varying levels of constraints and possibilities, similar spatial experiences and the need to rely on the automobile. Similarities in lived experiences, framed by suburban specialized and primarily low-density built environments and heavy dependence on the car, provide a common suburban culture to social groups otherwise segmented by age, income, ethnic/racial identity. It is important to acknowledge, however, that the existence of this shared culture does not mean that suburbanites have bought in all the

\footnotetext{
${ }^{1}$ The Toronto metropolitan region illustrates the difference in reliance on the automobile between suburbs and the central city. Outer suburbs register 24-hours, all-destinations car driver and passenger 2011 modal shares ranging from $83 \%$ to $89 \%$. Meanwhile in the part of the region originally developed before 1946, the equivalent figure is 50\% (Data Management Group, 2018).
} 
conditions leading to its existence. Whether supportive of automobility or not, they are locked in an environment and lifestyle that make dependence of the car a necessity (Sheller \& Urry, 2006).

The shared suburban culture can transmute into political expression. Some of the most usual political manifestations of suburban culture take the form of mobilizations to preserve features of suburbs perceived to be under threat. One target of NIMBY movements is the defence of the low-density character of the suburb in the face of densification initiatives. Not unexpectedly, these movements mirror resistance to the increased circulation associated with densification, which can perturb the delicate traffic balance of the super grid. The introduction of social mixing in previously homogenous neighbourhoods also fans NIMBY sentiments.

Electoral geography studies point to the determining role suburban areas play in the election of federal and state/provincial governments, reflecting their demographic weight (Gordon \& Janzen, 2013; Scott Thomas, 1998). They also note the conservativism of suburbs, which relates to the middle- and upper-class status of a large proportion of their population and, with direct relevance to their land-use and transportation patterns, to their tendency to rely on individual (notably singlefamily homes and the automobile) rather than collective forms of consumption (Kruse, 2005; Walks, 2004, 2006; Williamson, 2008). But electoral studies of suburbs acknowledge the existence of different voting patterns within the suburban realm and variations over time in these patterns. In the U.S., which party wins presidential elections is determined largely by how far the boundary between majority Democratic and Republican voters reaches out within the suburban realm. The further out it stretches, the stronger is the Democratic victory and vice versa for a Republican win (McKee \& Shaw, 2003). Finally, as is the case for other social categories, when perceived as under threat suburban culture is not immune to populist-type political mobilization (Müller, 2016).

\subsection{The Durability of the Suburban Land Use-Transportation Relationship}

The article is about tensions between stability and change in the suburb. It shares this theme with a recent article by Moos et al. (2015), which used a principal component analysis to identify these tensions within the suburbs of large Canadian metropolitan regions. The importance the present article gives to the enduring influence of automobility and associated land uses agrees with the findings of Moos et al. (2015) but, unlike the latter, which associates suburban stasis with different features of the suburban reality, the present article emphasizes the effect of one such stabilizing feature, the relationship between car dependence and land use, on most aspects of suburban life.

The central argument of the article is that while the socioeconomic makeup and economic base of the North
American suburb are in transition, one of its determining features, accounting for the enduring specificity of this urban environment, remains profoundly embedded. The article has identified the relationship between landuse patterns and automobile reliance as the defining durable characteristic of the North American suburb. The importance given to this feature stems from its influence on most activities taking place in suburban environments, and hence on most aspects of suburban life. The land use-transportation relationship mediates interactions taking place in suburbs: between home and work, home and retailing, home and workplaces, linkages between firms. In this perspective, it is premature to proclaim the emergence of a post-suburban phase. While the constituting parts of suburbs undergo transformation, the way these parts interact remains profoundly suburban. As the daily life of newcomers to the suburb adapts to the land-use patterns and journey dynamics of their new environment, they become suburbanized and partake in the suburban culture.

The article argues that the mutually reinforcing relationship between suburban land-use patterns and automobile dependency is likely to resist attempts at modifying the trajectory of suburban evolution, and thus be long-lasting. It has been present since early in the evolution of the post-WWII North American suburb and will in all probability persist in the foreseeable future. It constitutes the matrix wherein the suburb evolves, safeguarding some of its inherent features as it undergoes transformations.

This is not to deny the existence of transformative pressures on suburban land-use patterns. One driver of such pressures is the spatial expansion of metropolitan regions, which enhances the accessibility potential of inner suburbs and thus creates conditions favourable to their densification. Transformations of the suburb are also promoted by planning initiatives, inspired by smart growth and sustainable development, attempting to intensify the suburban realm and make it more walkingand public-transit conducive (Burchell, Downs, McCann, \& Mukherji, 2005; Calthorpe \& Fulton, 2001; Flint, 2006). A major theme present across North American metropolitan-scale plans is the recentralization of suburbs through the creation of hierarchies of multifunctional centres, from large centres, targeting as their catchment areas entire quadrants of metropolitan regions, to neighbourhood-scale centres of complete communities (Filion, Kramer, \& Sands, 2016). There are, however, many obstacles in the way of planning attempts at modifying suburban land use-transportation dynamics. These obstacles are related to: limited financial capacity to fund public transit infrastructures within the suburban realm; resistance to the modification of a built environment developed in function of the car; and insufficient planning institutional capacity (Scheer, 2010).

Land use-transportation features of suburbs and their repercussions owe their durability to feedback loops consisting of decisions taking place at different 
scales and impacting development and daily behaviour. These decisions concern transportation infrastructures and services, planning and development, choices of individuals regarding residential and work location as well as consumption options, and the political preferences of suburbanites. The next sections introduce two brief case studies intended to capture several scales at which such decisions are made. The selection of the case studies also purports to illustrate the wide range of mechanisms reinforcing the core features of North American suburbs. The first case study shows that even major suburban multifunctional centres, meant to disseminate public transit- and walking-oriented environments across the suburban realm, have difficulties breaking from the prevailing suburban built form and transportation patterns. The second case focusses on political resistance to transformative initiatives. It documents how the perception of threats to the suburban specificity can give rise to political expressions of suburban populism. Both case studies originate from the Toronto metropolitan region. Illustrating a continental-wide phenomenon may seem an excessive burden to place on a single metropolitan region. But while circumstances associated with mechanisms supporting core features of suburbs vary between metropolitan regions, and indeed from sector to sector within these regions, we can expect a degree of similarity among these mechanisms since they sustain identical features present across the continental suburban realm.

\section{Methods: Recentralization's Failures and Suburban Populism}

The first case study concentrates on four suburban multifunctional centres in the Toronto metropolitan region. It relies on a land-use analysis of these centres to verify the extent to which they provide a walkable and transitoriented environment, which constitutes, as stated in planning objectives, an alternative to prevailing suburban development and transportation patterns. Measurements of the different land uses present in the four centres were made on Google Earth Pro ${ }^{\mathrm{TM}}$ aerial imagery. The second case study identifies the themes raised by Rob Ford during the 2010 City of Toronto mayoralty race, which he won thanks to overwhelming support from the suburban sectors of the city. The article concentrates on those themes that refer to the suburban lifestyle and to threats to this lifestyle from actual or intended policies stemming from alleged anti-suburban attitudes on the part of so-called downtown elites. The themes were identified through a search of two newspapers, the Toronto Star and the Globe and Mail, over the period covered by the 2010 electoral campaign, which ran from September 10 , which marked the end of the candidates' nomination period, to October 25, election day (data from The Sun, a right-wing populist tabloid were not available). All articles over this period where the name of Rob Ford appeared were consulted, which led to the identification of 199 mentions of electoral campaign themes.

\section{Attempts at Recentralization}

The Ontario Provincial Government adopted in 2006 a comprehensive plan, the Growth Plan, for a large region focussed on Toronto (Ontario, 2013). The plan, which has been given power of law, is meant to reduce sprawl, increase reliance on public transit and protect natural and rural areas. One of its main proposals is the creation of a network of 25 urban growth centres (UGCs), intended to become high-density pedestrian- and public transithospitable multifunctional centres (Ryan \& Frank, 2009). Relying on the further development and redesigning of existing concentrations of activities and the creation of new such concentrations, the UGC strategy purports to create walking- and public transit-conducive nodes within the otherwise car-oriented suburban realm. It also aims to provide a measure of high-density recentralization, a condition for effective public-transit services, in the low-density and spatially segregated suburban environment. Regional and municipal planning agencies have aligned their objectives regarding UGCs with those of the Growth Plan.

This section investigates the four most developed UGCs within the Toronto metropolitan region suburban realm. Three of these centres grew around regional shopping malls: Mississauga City Centre, Scarborough Town Centre and Pickering Town Centre. They all border an expressway and Scarborough Town Centre and Pickering Town Centre are served by rail transit, LRT in the first case and regular commuter train service in the second. Mississauga is served by a BRT route and is the site of a major bus terminal. The history of the fourth UGC, North York Centre, is different as is its accessibility. North York Centre is the outcome of the redevelopment of a lowrise 1940s and 1950s retail strip. Along with abutting an expressway, North York Centre is served by two subway lines and three subway stations. Without a regional mall, the retail component of North York Centre is much smaller than that of the other three UGCs. The number of residential units and the amount of office space are, however, much larger than in the three other centres (see Table 1).

The question is: how much do these centres depart from the prevailing suburban land-use and transportation patterns, in other words, how much do they conform to their transformative planning objectives? Do they bring a different land use-transportation dynamic to the suburb, which is favourable to walking and public transit, or do they reproduce in a higher density environment present suburban journey patterns? Land-use measurements presented in Table 2 provide an indication of the extent to which the four UGCs have achieved their planning objectives. Just as the conduciveness to walking of a tightly built environment has been widely documented, so has the walking inhospitality of wide arterials and surface parking lots (Gehl, 2011; Hess, Vernez Moudon, Snyder, \& Stanilov, 1999; Saelens \& Handy, 2008; Southworth, 2005; Vernez Moudon et al., 2006). 
Table 1. General characteristics of the four main Toronto suburban UGCs.

\begin{tabular}{llllll}
\hline UGC & Area $\left(\mathrm{km}^{2}\right)$ & Type of UGC & $\begin{array}{l}\text { Highest order of } \\
\text { public transit }\end{array}$ & Residential units & Office space $\left(\mathrm{m}^{2}\right)$ \\
\hline Mississauga City Centre & 2.22 & Mall-focussed & BRT & 16,473 & 396,202 \\
\hline Scarborough Town Centre & 1.17 & Mall-focussed & LRT & 6,586 & 219,274 \\
\hline Pickering Town Centre & 0.64 & Mall-focussed & Commuter Train & 1,032 & 35,867 \\
\hline North York Centre & 1.42 & $\begin{array}{l}\text { Suburban } \\
\text { Redevelopment }\end{array}$ & Subway & 25,162 & 731,039 \\
\hline
\end{tabular}

An important proportion of the area of UGCs catering to the automobile points to conformity to the suburban land use-transportation norm, while a high building footprint coverage suggests a pedestrian-conducive environment. Land-use conditions that are favourable to public transit are largely similar to those associated with a hospitable pedestrian environment. Indeed, most people walk to and from public-transit stations, and compact multifunctional environments encourage both public-transit use and walking. Another factor of walkability discussed in the literature is the presence of small blocks as gauged by a high number of intersections.

Relative to North York Centre, in the three mallfocussed UGCs, the proportion of the total area taken by building footprint is low, while that occupied by parking is elevated (Table 2). Likewise, the total area of the centres divided by the number of intersections is much larger in these three centres than it is in North York Centre, which suggests a predominance of large blocks. These measures indicate some similarity in the three mall-focussed UGCs with the land-use adaptation to the car and the poor walking conditions characterizing the suburb. On the other hand, North York Centre presents a configuration that is much less accommodating of the car and more hospitable to walking. Contrary to the other three UGCs, it brings to the suburban realm an alternative built environment providing land-use conditions that are more public transit- and walking-friendly.

One explanation for the different configurations and journey dynamics of the UGCs under study relates to their respective history. Their origins cast a long shadow. Mall-focussed centres have been developed from the start in a car-oriented fashion, that is, as a large shopping mall surrounded by a wide parking expanse. This legacy lives on as the important proportion of their area devoted to parking testifies. On the other hand, as North York Centre is the outcome of the piecemeal redevelopment of a low-density early suburban grid pattern, it devotes a lesser proportion of space to parking and registers a low area/intersections quotient.

There is another reason for the difference in the automobile orientation of the UGCs. The three mall-focussed UGCs act as retail centres for large suburban catchment areas. Given the car-oriented land use-transportation relationship of these areas, most people drive to shop in the three mall-focussed UGCs. In this sense, the journey pattern and the spatial structure of these UGCs are to a large extent determined by their surrounding suburban environment. In their case, it is ambient suburban areas that influence UGCs rather than the other way around. Their centrality role within the suburban realm takes place at the expense of their planning objectives calling for less reliance on the car and more public-transit use and walking. Findings from these three UGCs raise doubts about reliance on the development of large multifunctional centres as beachheads within the suburban realm meant to alter the suburban relationship between land-use patterns and automobile dependence.

The North York Centre situation is different. It is dominated by offices and high-rise housing rather than by retailing. Not only does its superior public-transit accessibility account for lower car modal shares, and hence less need for parking, but in North York Centre parking fees are a disincentive to driving. Parking fees also make it financially feasible to build underground and multi-storey parking facilities, thus limiting the footprint of parking. In the other three UGCs, intense competition from malls elsewhere within the suburban realm prevents the introduction of parking fees. Unlike the other UGCs, North York Centre presents a morphology and journey patterns that

Table 2. Building footprint, parking coverage and area/intersection quotient of the four Toronto suburban UGCs.

\begin{tabular}{llll}
\hline UGC & $\begin{array}{l}\text { Building footprint } \\
\text { (\% of total area) }\end{array}$ & $\begin{array}{l}\text { Parking coverage } \\
\text { (\% of total area) }\end{array}$ & $\begin{array}{l}\text { Total area/intersections } \\
\left(\mathrm{m}^{2}\right)\end{array}$ \\
\hline Mississauga City Centre & 17.47 & 25.49 & 40,847 \\
\hline Scarborough Town Centre & 15.58 & 28.60 & 40,152 \\
\hline Pickering Town Centre & 21.87 & 38.25 & 65,982 \\
\hline North York Centre & 36.48 & 11.57 & 20,719 \\
\hline
\end{tabular}


contrast to a large extent with those of the surrounding suburban realm. It operates more like a downtown than a conventional suburban area. But it is important to acknowledge the exceptional circumstances of North York Centre. First, its redevelopment took place in an old suburban sector with a tight grid pattern, which is an unusual configuration in post-war suburban areas. Second, it is extraordinarily advantaged from a public transit perspective.

\section{Suburban Populist Reactions}

The present City of Toronto is the outcome of the 1997 amalgamation of six municipalities (including the former City of Toronto) federated into what was then Metro Toronto. The built environment of the former City of Toronto was developed before 1946 as was to some extend that of two small adjacent municipalities. The other former municipalities, which occupy most of the territory of the new City of Toronto and account for a majority of its population, were developed mostly between 1946 and 1971, therefore according to the car-oriented standards of the time.

From 2003 to 2010, the city was administered by a centre-left mayor, David Miller. Over these years, he was involved in some prestige initiatives such as the successful Toronto bid for the Pan Am Games and waterfront redevelopment projects. He strongly endorsed the Transit City plan, which consisted in the creation of six LRT lines, to take place mostly in City of Toronto suburban areas. The mandate of David Miller coincided with a rapid redevelopment of Downtown Toronto, which acquired an important residential dimension and became the site of many city-sponsored improvements. The transformation of Downtown Toronto projected the image of a city that was courting members of the creative class, the main occupants of mushrooming condo towers. A long garbage strike over the summer 2009 marred the second term of David Miller. In 2010, he announced that he would not to run for a third term. In the two elections he won, David Miller performed best in central wards, but also received a respectable proportion of votes from the suburbs, which explains his two city-wide electoral victories.

During the entire 2010 Toronto mayoralty campaign, polls were dominated by Rob Ford, a conservative council member since 2000. Consistent with his right-wing agenda, Rob Ford played heavily the fiscal responsibility card. He depicted city spending as out of control and, therefore, the taxpayers as unnecessarily burdened by escalating municipal taxes. A main slogan of his campaign was to get rid of the "gravy train" at City Hall. His attacks especially targeted "spendthrift" councillors. He promised to reduce the number of councillors by half and radically cut the budget of their offices. It follows that, as portrayed by Table 3, most of the references to his campaign themes reported in the Toronto Star and Globe and Mail pertained to these financial concerns.

But there were two other dimensions to the Rob Ford campaign, both of which more narrowly targeted at sub- urban voters. A second Rob Ford slogan was "stopping the war on the car" (Walks, 2015). According to Rob Ford, car drivers were victimized by planning initiatives taking road space away from them, notably cycling lanes and LRT lines with their own right of way. His program committed to give road space back to the car by removing cycling lanes and even eliminating the existing streetcar system. It also pledged to prevent further incursions on automobile road space by cancelling the Transit City program. The only form of public transit that was acceptable to Rob Ford were tunnelled subways because they did not interfere with road traffic. He kept silent, however, on the fact that a given public transit budget would deliver much more LRT than subway coverage and that most suburban areas do not post sufficient density to justify the presence of subways. His public transit agenda clearly demonstrated that his transportation proposals were targeted more at automobile than public-transit users. These platforms resonated well with the suburban automobile-dependent constituency. It promised to prevent LRT rights of way and cycling lanes from reducing the car capacity of suburban arterials. Also, many saw the removal of streetcars as a means of accelerating the drive from the suburbs to Downtown Toronto, with little concern for the effect this would have on the nearly 300,000 daily streetcar users.

Table 3. Themes raised during the Rob Ford campaign (number of times mentioned). Source: articles mentioning Rob Ford in the Toronto Star (2010) and Globe and Mail (2010) published between September 10 and October 25, 2010.

\section{Social agenda}

Anti-gay statements 3

Limit additional immigration $\quad 10$

\section{Financial agenda}

Tax and spending cuts

End the "gravy train"

Cut existing programs

Cut number and expenses of councillors $\quad 15$

Dysfunctional City Hall

Law and order

Hire 100 additional police

Transportation

Build subways

Anti LRT and streetcar

End "war on cars"

Against elites and Central City

Critique "downtown elites"

Privileged central areas

Total mentions of themes

The other facet of the Rob Ford message directed at the City of Toronto suburbs described as "downtown elites" the individuals he held responsible for the neglect of the 
suburbs by the City of Toronto and for plans that transgressed the suburban car-oriented culture. As he defined it, the downtown elite category included the previous mayor, the 2010 mayoralty candidates he ran against, left-leaning councillors, planners, most of the media, environmentalists and even cyclists. In true populist form, he held external actors responsible for the woes facing the suburbs, setting the terms for an "us and them" political discourse: the "common folks of the suburbs" versus disconnected downtown elites. Rob Ford also contrasted the large sums (wasted in his view) lavished on central parts, especially the waterfront, with examples of suburban neglect.

The electoral results map matched the original period of development of the different wards within the city. Wards originally developed before 1946 voted against Rob Ford and those whose development took place after 1945 supported him. The lesson from the victorious Rob Ford electoral campaign is not that there is an inherent inclination in the suburbs for right-wing political themes. Previous and later City of Toronto suburban voting patterns indicate that suburbs can adopt other voting patterns. Also, there were other facets to the Rob Ford populist political message than the war on the car and suburban alienation (Kipfer \& Saber, 2014). The case study does show, however, that when circumstances are favourable, suburbs can be electorally mobilized around a populist discourse emphasizing their common culture revolving around reliance on the car and associated landuse features. It deserves to be emphasized that suburban portions of the City of Toronto are highly diversified from an ethnic/racial and income perspective. Issues brought up by Rob Ford clearly transcended the social diversity of suburbs. The campaign also illustrates how what was pictured as challenges to the suburban culture provoked a political backlash, which prevented the implementation of the Transit City program. It probably helped the case Rob Ford was making that the provincial Growth Plan depicted conventional suburban development as a non-sustainable urban form in need of densification and increased public-transit reliance. Under the short-lived Rob Ford administration (due to scandals and then illness and his death) the transportation status quo was maintained in suburban areas (Doolittle, 2014).

As an epilogue to this story, in June 2018, Doug Ford, the brother of Rob Ford who shares his political values and electoral base, was elected Premier of Ontario. Like for his brother's campaign eight years earlier, the central plank of the electoral platform of Doug Ford was fiscal responsibility: controlling provincial spending and eliminating the deficit while reducing income tax. But the political promise that arguably best chimed with his supporters was to lower the provincial tax on gasoline by ten cents a litre. He won the provincial election by a wide margin, in large part thanks to the support of a large majority of Toronto-region suburban ridings (37 of 44), which are all highly dependent on driving.

\section{Conclusion: Suburban Distinctiveness and Stability}

The argument of the article has unfolded in three stages. First, while the article has acknowledged the existence of profound transformations over the past decades in the nature of the constituting parts of the North American suburb, it has also identified a great deal of consistency over time in how it operates. The social groups and activities present in suburbs have changed, but the structuring features of the built environment in which they live and operate, along with the mode of transportation mediating their interactions, have remained largely stable since the early post-WWII period. Therefore, the article refrained from proclaiming the mutation of the suburb into a new post-suburban entity. Second, the article contended that the characteristic that best captures the specificity of the North American suburb is the relationship between, on the one hand, a generally low-density built form that is functionally specialized and adapted to the car, and on the other, a nearly generalized dependence on the automobile. The reason for the concentration on this relationship is that it reverberates on most aspects of the suburb. It thereby undergirds daily life in the suburb and the suburban culture to which the everyday behaviour of suburbanites gives rise. Third, the article has identified mechanisms maintaining this relationship in place. These mechanisms account for the large measure of consistency in suburban land-use and transportation patterns from the early post-war era, as well as for their likely future durability. One such mechanism is the shaping by prevailing land use-transportation patterns of different scales of decision-making leading to a mutual adaptation between the built environment and predominant forms of transportation. Such decisions run the gamut from macro-scale planning and development decisions, determining the main orientations of suburban development, to daily journey choices made by residents. Another mechanism comprises the wide range of political actions in defence of the suburban lifestyle and of the built form and transportation patterns supporting it.

The two Toronto case studies cast light on how these mechanisms operate by focussing on a specific form of suburban development and a political event. The case studies thus focused on a narrow range of mechanisms, considered in their respective empirical context, preserving the identified specificity of the suburb. The UGCs case study has shown that in most instances these centres have been incapable of overcoming the car-orientation of the surrounding suburban environment, resulting in the important place taken by the car in their configuration. They have failed to break the mutual influence between UGC development decisions and journey choices bearing the mark of low-density car-dependent catchment areas. The second case has investigated the themes raised during a political campaign that mobilized suburbanites around the preservation of their suburban culture and lifestyle, portrayed as under treat from hos- 
tile external forces. It has shown that this successful mobilization has indeed led to the overturning of policies that would have somewhat abated the dominance of the car within City of Toronto suburban areas.

The article raises concerns about the likely effectiveness of current planning efforts at transforming the suburb so as to make it more environmentally sustainablethe theme of this issue of Urban Planning. Its purpose is not to discourage such efforts but rather to make planners and policy-makers aware of the entrenched nature of the prevailing suburban land use-transportation dynamic and of the need to devise strategies capable of addressing and overcoming this dynamic.

\section{Acknowledgments}

The article has drawn from the findings of two research grants, the Major Collaborative Research Initiative grant entitled Global Suburbanism and the Insight grant entitled From Urban Dispersion to Recentralization: Lessons from Canadian Planning Initiatives. Both grants were funded by the Social Science and Humanities Research Council of Canada.

\section{Conflict of Interests}

The author declares no conflict of interests.

\section{References}

Adams, M. (2003). Fire and ice: The United States, Canada and the myth of converging values. Toronto: Penguin Canada.

Badoe, D. A., \& Miller, E. J. (2000). Transportation-land use interaction: Empirical findings in North America, and their implications for modeling. Transportation Research Part D: Transport and Environment, 5(4), 235-263.

Bae, C.-H. C. (2004). Urban sprawl in Western Europe and the United States. London: Routledge.

Banham, R. (1971). Los Angeles: The architecture of four ecologies. New York, NY: Harper and Row.

Blumenberg, E. (2004). En-gendering effective planning: Spatial mismatch, low-income women, and transportation policy. Journal of the American Planning Association, 70(3), 269-281.

Boustan, L. P. (2010). Was postwar suburbanization 'white flight'? Evidence from the Black migration. Quarterly Journal of Economics, 125(1), 417-443.

Bresnahan, T., \& Gambardella, A. (Eds.). (2004). Building high-tech clusters: Silicon Valley and beyond. Cambridge: Cambridge University Press.

Burchell, R. D., Downs, A., McCann, B., \& Mukherji, S. (2005). Sprawl costs: Economic impacts of unchecked development. Washington, DC: Island Press.

Calthorpe, P., \& Fulton, W. (2001). The regional city: Planning for the end of sprawl. Washington, DC: Island Press.
Carr, C. M. R., \& Whitehand, J. W. R. (2001). Twentiethcentury suburbs: A morphological approach. London: Routledge.

Cervero, R. (2013). Suburban gridlock. New Brunswick, NJ: Transaction Books.

Charmes, E. (2010). Cul-de-sac, superblocks and environmental areas as supports of residential territorialisation. Urban Design, 15(3), 357-374.

Data Management Group. (2018). TTS: Transportation tomorrow survey. University of Toronto Transportation Research Institute. Retrieved from dmg.utoronto.ca

de Certeau, M. (1984). The practice of everyday life. Berkeley, CA: University of California Press.

Dear, M., \& Flusty, S. (1998). Postmodern urbanism. Annals of the Association of American Geographers, 88(1), 50-72.

Doolittle, R. (2014). Crazy town: The Rob Ford story. Toronto: Penguin Canada.

Filion, P., Kramer, A., \& Sands, G. (2016). Recentralization as an alternative to urban dispersion: Transformative planning in a neoliberal context. International Journal of Urban and Regional Research, 40(3), 658-678.

Flint, A. (2006). This land: The battle over sprawl and the future of America. Baltimore, MD: Johns Hopkins University Press.

Franck, K., \& Stevens, Q. (Eds.). (2006). Loose space: Possibility and diversity in urban life. London: Routledge.

Gehl, J. (2011). Life between buildings: Using public space. Washington, DC: Island Press.

Globe and Mail. (2010). The Globe and Mail.

Gordon, D. L. A., \& Janzen, M. (2013). Suburban nation? Estimating the size of Canada's suburban population. Journal of Architectural and Planning Research, 30(3), 197-220.

Harris, R. (2004). Creeping conformity: How Canada became suburban 1900-1960. Toronto: University of Toronto Press.

Hayden, D. (2003). Building suburbia: Green fields and urban growth 1820-2000. New York, NY: Vintage Books.

Hess, P. M., Vernez Moudon, A., Snyder, M. C., \& Stanilov, K. (1999). Site design and pedestrian travel. Transportation Research Record, 1674, 9-19.

Highmore, B. (Ed.). (2002a). The everyday life reader. London: Routledge.

Highmore, B. (2002b). Everyday life and cultural theory: An introduction. London: Routledge.

Hirt, S. A. (2014). Zoning in the USA: The origins and implications of American land-use regulations. Ithaca, NY: Cornell University Press.

$\mathrm{Hu}$, L. (2015). Job accessibility of the poor in Los Angeles: Has suburbanization affected spatial mismatch? Journal of the American Planning Association, 81(1), 30-45.

Keil, R., \& Addie, J.-P. D. (2015). 'It's not going to be suburban, it's going to be all urban': Assembling postsuburbia in the Toronto and Chicago regions. International Journal of Urban and Regional Research, 39(5), 
892-911.

Kelly, B. M. (1993). Expanding the American dream: Building and rebuilding Levittown. Albany, NY: State University of New York Press.

Kipfer, S., \& Saber, P. (2014). From "revolution" to farce? Hard-right populism in the making of Toronto. Studies in Political Economy, 93, 127-151.

Kruse, K. M. (2005). White flight: Atlanta and the making of modern conservatism. Princeton, NJ: Princeton University Press.

Lee, J., Hong, S., \& Park, V. (2017). Predictable surprise: The spatial and social morphology of aging suburbs in the U.S. metropolitan areas. Sustainability, 9(3). https://doi.org/10.3390/su9030458

Lefebvre, H. (1991). Critique of everyday life: Volume 1 Introduction. London: Verso.

Li, W. (2009). Ethnoburb: The new ethnic community in urban America. Honolulu, HI: University of Hawai'i Press.

Li, W., Skop, E., \& Yu, W. (2016). Enclaves, ethnoburbs, and new patterns of settlement among Asian immigrants. In M. Zhou \& A. C. Ocampo (Eds.), Contemporary Asian America: A multidisciplinary reader (3rd ed., pp. 193-216). New York, NY: New York University Press.

Lo, L., Preston, V., Anisef, P., Basu, R., \& Wang, S. (2015). Social infrastructure and vulnerability in the suburbs. Toronto: University of Toronto Press.

Lucy, W., \& Phillips, D. L. (2000). Confronting suburban decline: Strategic planning for metropolitan renewal. Washington, DC: Island Press.

Mace, A. (2013). City suburb: Placing suburbia in a postsuburban world. London: Routledge.

Marshall, A. (2000). How cities work: Suburbs, sprawl, and the roads not taken. Austin, TX: University of Texas Press.

McKee, S. C., \& Shaw, D. R. (2003). Suburban voting in presidential elections. Presidential Studies Quarterly, 33(1), 125-144.

Moos, M., Mendez, P., McGuire, L., Wyly, E., Kramer, A., Walter-Joseph, A., \& Williamson, M. (2015). More continuity than change? Re-evaluating the contemporary socio-economic and housing characteristics of suburbs. Canadian Journal of Urban Research, 24(2), 64-90.

Mozingo, L. A. (2011). Pastoral capitalism: A history of suburban corporate landscapes. Cambridge, MA: MIT Press.

Müller, J.-W. (2016). What is populism? Philadelphia, PA: University of Pennsylvania Press.

Murphy, A. K. (2007). The suburban ghetto: The legacy of Herbert Gans in understanding the experience of poverty in recently impoverished American suburbs. City and Community, 6(1), 21-37.

Ontario. (2013). Growth plan for the Greater Golden Horseshoe 2006 (office consolidation June 2013). Toronto: Ministry of Infrastructure \& Queen's Printer for Ontario.
Park, R. E., Burgess, E. W., \& McKenzie, R. D. (1925). The city. Chicago, IL: University of Chicago Press.

Phelps, N. A. (2015). Sequel to suburbia: Glimpses of America's post-suburban future. Cambridge, MA: MIT Press.

Phelps, N. A., Wood, A. M., \& Valler, D. C. (2010). A postmodern world? An outline of a research agenda. Environment and Planning A: Economy and Space, 42(2), 366-383.

Phelps, N. A., \& Wu, F. (2011). Introduction: International perspectives on suburbanization. A post-suburban world? In N. A. Phelps \& F. Wu (Eds.), International perspectives on suburbanization: A post-suburban world? (pp. 1-11). London: Palgrave Macmillan.

Pushkarev, B., \& Zupan, J. (1977). Public transportation and land use policy. Bloomington, IN: Indiana University Press.

Rowe, P. G. (1991). Making a middle landscape. Cambridge, MA: MIT Press.

Ryan, S., \& Frank, L. F. (2009). Pedestrian environments and transit ridership. Journal of Public Transportation, 12(1), 39-57.

Saelens, B. E., \& Handy, S. L. (2008). Built environment correlates of walking: A review. Medicine and Science in Sports and Exercise, 40(7), S550-S566.

Scheer, B. C. (2010). The evolution of urban form: Typology for planners and architects. Chicago, IL: Planners Press.

Scott Thomas, G. (1998). The United States of suburbia: How the suburbs took control of America and what they plan to do with it. Amherst, NY: Prometheus.

Sheller, M., \& Urry, J. (2006). Mobile technologies of the city. London: Routledge.

Short, J. R., Hanlon, B., \& Vicino, T. J. (2007). The decline of inner suburbs: The new suburban gothic in the United States. Geography Compass, 1(3), 641-656.

Southworth, M. (2005). Designing the walkable city. Journal of Urban Planning and Development, 131(1), 246-257.

Southworth, M., \& Ben-Joseph, E. (1995). Street standards and the shaping of suburbia. Journal of the American Planning Association, 61(1), 65-81.

Southworth, M., \& Owens, P. M. (1993). The evolving metropolis: Studies of community neighborhood, and street form at the urban edge. Journal of the American Planning Association, 59(3), 271-287.

Spinney, J. E. L., Scott, D. M., \& Newbold, K. B. (2009). Transport mobility benefits and quality of life: A timeuse perspective of elderly Canadians. Transport Policy, 16(1), 1-11.

Teaford, J. (1997). Post-suburbia: Government and politics in the edge cities. Baltimore, MD: Johns Hopkins University Press.

Teaford, J. (2011). Suburbia and post-suburbia: A brief history. In N. A. Phelps \& F. Wu (Eds.), International perspectives on suburbanization: A post-suburban world? (pp. 15-34). London: Palgrave Macmillan.

Toronto Star. (2010). Toronto Star. 
van Wee, M. (2002). Land use and transport: Research and policy challenges. Journal of Transport Geography, 10(4), 259-271.

Vernez Moudon, A., Lee, C., Cheadle, A. D., Garvin, C., Johnson, D. B., Schmid, T. L., \& Weathers, R. D. (2006). Attributes of environments supporting walking. American Journal of Health Promotion, 21(5), 448-459.

Waldie, D. J. (1996). Holy land: A suburban memoir. New York, NY: Norton.

Walks, R. A. (2004). Suburbanization, the vote, and changes in federal and provincial representation and influence between inner cities and suburbs in large Canadian urban regions, 1945-1999. Urban Affairs Review, 39(4), 411-440.

Walks, R. A. (2006). The causes of city-suburban political polarization? A Canadian case study. Annals of the Association of American Geographers, 96(2), 390-414.

Walks, R. A. (2014). Driving the vote? Automobility, ideology, and political partisanship. In R. A. Walks (Ed.), The urban political economy and ecology of automobility: Driving cities, driving inequality, driving politics
(199-220). London: Routledge.

Walks, A. (2015). Stopping the 'war on the car': Neoliberalism, Fordism, and the politics of automobility in Toronto. Mobilities, 10(3), 402-422.

Walks, R. A., \& Tanter, P. (2014). Driving mobility, slowing down the poor: Effective speed and unequal mobility. In R. A. Walks (Ed.), The urban political economy and ecology of automobility: Driving cities, driving inequality, driving politics (pp. 129-151). London: Routledge.

Weitz, J., \& Crawford, T. (2012). Where the jobs are going: Job sprawl in U.S. metropolitan regions, 2001-2006. Journal of the American Planning Association, 78(1), 53-69.

Williamson, T. (2008). Sprawl, spatial location, and politics: How ideological identification tracks the built environment. American Politics Research, 36(6), 903-933.

Zhang, M. (2006). Travel choice with no alternative: Can land use reduce automobile dependence? Journal of Planning Education and Research, 25(3), 311-326.

\section{About the Author}

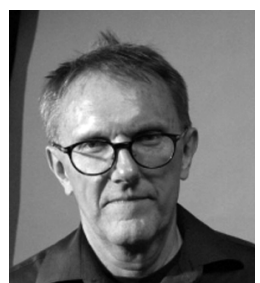

Pierre Filion is a Professor at the School of Planning of the University of Waterloo. His areas of research include the relation between transportation and land use, metropolitan-scale planning and suburban areas. He has co-edited a book on suburban infrastructure about to be published by the University of Toronto Press, and is presently investigating the dynamics of metropolitan sub centres across Canada. 